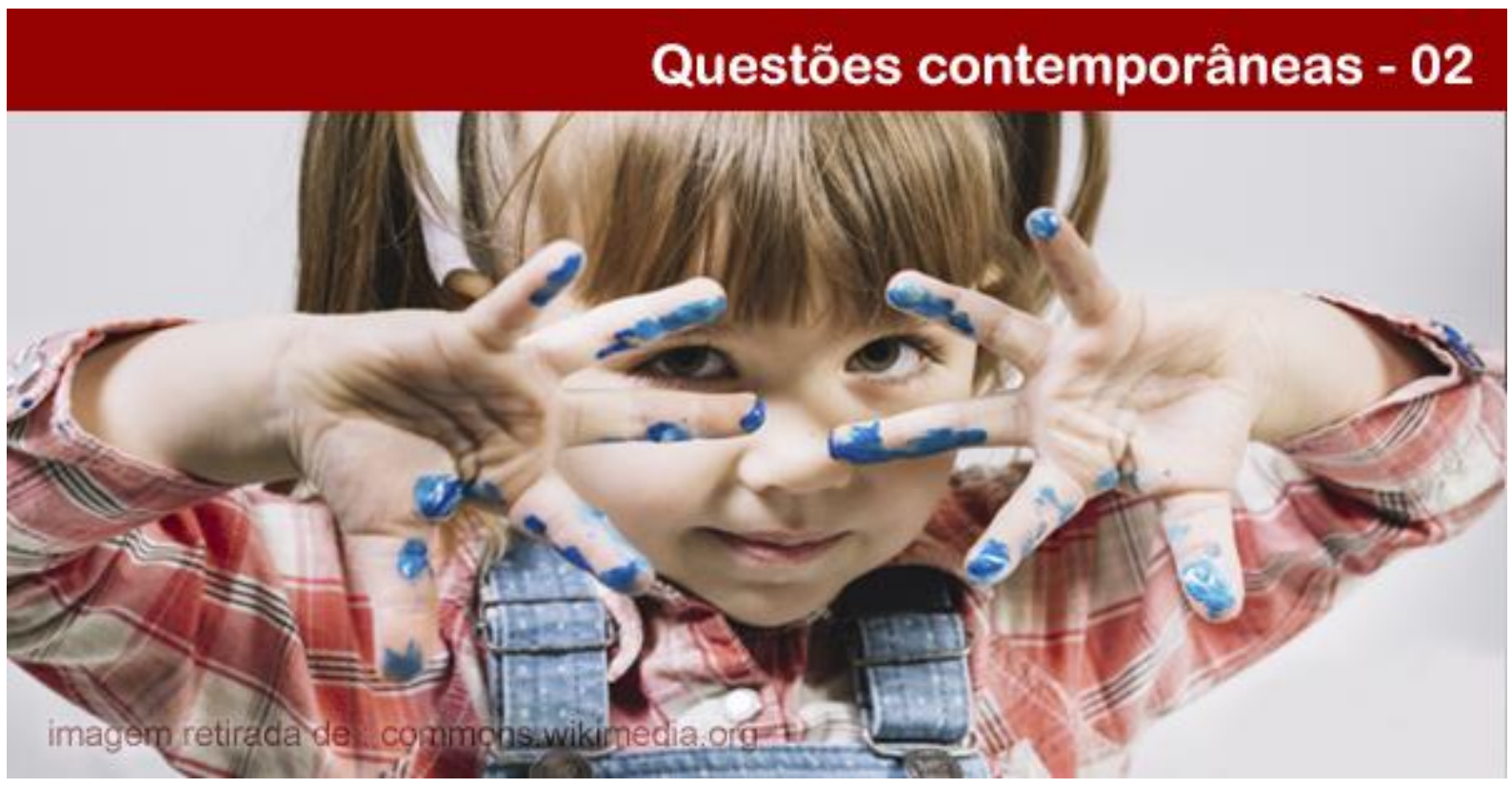

\title{
EDUCAÇÃO INFANTIL E SUBJETIVAÇÃO DA CRIANÇA NA SOCIEDADE DE CONSUMO
}

\author{
Luciana Martins Quixadá \\ Doutora em Educação pela Universidade Federal do Ceará (UFC). Mestre em Psicologia pela Universidade de \\ Brasília (UnB).Graduadaem Psicologia pela UFC.E-mail: luciana.martins@uece.br.
}

Resumo: Pretende-se problematizar sobre as condições de participação política da criança na sociedade de consumo, apontando o quanto a educação infantil tem a fazer para tornar-se uma via potencializadora que supere práticas de exclusão e de fragilidade dos laços sociais. Importa na atualidade uma discussão crítica sobre os ideais de uma cultura que desautoriza muitos dos seus membros, negando suas capacidades de realizar mudanças significativas em suas experiências cotidianas. Metodologicamente, análises bibliográficas pautadas na teoria crítica e histórico-cultural, articularam-se aos resultados de uma pesquisa de tese, visando refletir sobre a constituição da autonomia da criança em ambiente escolar na sociedade de consumo. Considerando a dinamicidade das relações e dos espaços sociais, a escola precisa se reinventar, injetando práticas pedagógicas que favoreçam junto à criança sua participação nos projetos coletivos e que fomentem sua capacidade criativa como forma de viabilizar seu desenvolvimento social e moral, bem como o exercício de sua cidadania.

Palavras-chave: Criança. Sociedade. Educação.

\section{CHILD EDUCATION AND SUBJECTIVATION OF THE CHILD IN THE CONSUMER SOCIETY}

Abstract: It is intended to problematize on the conditions of political participation of the child in the consumer society, pointing out how much the child education has to do to become a potential way that overcomes practices of exclusion and fragility of the social bonds. A critical discussion of the ideals of a culture that disavows many of its members, denying their ability to make meaningful changes in their everyday experiences, is currently important. Methodologically, bibliographic analyzes based on critical and historical-cultural theory, were articulated to the results of a thesis research, aiming to reflect on the constitution of autonomy in children in school environment in the consumer society. Considering the dynamics of relationships and social spaces, the school needs to reinvent itself, injecting pedagogical practices that favor the child's participation in collective projects and that promote their creative ability as a way to enable their social and moral development, as well as the exercise of their citizenship.

\section{POLÊM!CA $\mid$ LABORE (3)}

Polêmica - Revista Eletrônica da Uerj - Rua São Francisco Xavier, 524, $1^{\circ}$ andar bloco D, sl.1001 • Tels.: +55 21 2334-4088 / 4087 • http://www.e-publicacoes.uerj.br/index.php/polemica/index http://www.labore.uerj.br • laboreuerj@yahoo.com.br 
Keywords: Child. Society. Education.

\section{Introdução}

Do lado de dentro, duas crianças brancas brincavam no parquinho do condomínio. Estavam no balanço, bem vestidas, riam bastante e apenas se viam mutuamente, enquanto, do lado de fora das grades de "segurança", havia outra menina de pele negra, sem camisa nem calçados nos pés. Estava nos braços da mãe, e devia ter em torno de quatro anos e segurava com força aquelas grades, olhando glutona e sorrindo para aquela diversão que não podia ser sua. A mãe talvez pensasse que parar ali por alguns instantes com a filha pudesse ser uma forma de proporcionar-lhe certo prazer. Então, ficaram.

Haveria uma sensação de impotência e/ou desejo de ser igual? O que se vê prontamente, no entanto, é o apartheid entre "os de dentro" e "os de fora". Talvez o sorriso da menina "de fora" era, muito provavelmente, porque ainda não percebia a imensa separação social entre ela e aquelas. Assim, naquele momento, divertia-se só de ver a brincadeira alheia, mas quais brincadeiras também produzia essa menina "de fora"? A escola que ela frequentava funcionava como um dispositivo emancipador ou legitimador dessa ordem excludente?

Essa foi uma cena vista no cotidiano da autora desse artigo, um exemplo de muitas situações semelhantes que estão presentes rotineiramente na realidade brasileira e em tantas outras. As questões que essa cena suscitou permanecem, pois não se realizou nenhuma investigação mais detida sobre a vida dessa menina. Contudo, essa observação inicial foi o mote que levou às reflexões apresentadas nesse trabalho. Metodologicamente, foram realizadas análises bibliográficas pautadas nas teorias crítica e histórico-cultural, articulando-as aos resultados da pesquisa de tese da autora desse texto. Desse modo, pretende-se, a partir daí, problematizar acerca das relações de poder estabelecidas na sociedade de consumo que afetam o processo de constituição subjetiva e a democratização dos bens de consumo, considerando os alicerces da participação política ou não nessa sociedade. Em tempos de ameaça à democracia no Brasil, esse trabalho é pertinente, pois busca pensar essas relações, especificamente no ambiente escolar. Além disso, considera-se nesse texto que a educação infantil pode tornar-se uma via na luta para a superação da exclusão social, caso as práticas pedagógicas na escola favoreçam a participação política das crianças, isto é, favoreçam o desenvolvimento de sujeitos emancipados (ADORNO, 2011).

\section{POLÊM!CA $\mid$ LABORẸ}

Polêmica - Revista Eletrônica da Uerj - Rua São Francisco Xavier, 524, $1^{\circ}$ andar bloco D, sl.1001 • Tels.: +55 21 2334-4088 / 4087 • http://www.e-publicacoes.uerj.br/index.php/polemica/index http://www.labore.uerj.br • laboreuerj@yahoo.com.br 
As reflexões aqui apresentadas partem ainda da ideia de infância enquanto fenômeno social e, portanto, deve-se pensá-la, sob a ótica de Bourdieu (2009), ou seja, inserida em um espaço de produção simbólica em que diversos elementos a envolvem e lhe dão sentido portanto, falemos de infâncias, especialmente para destacar a abissal desigualdade manifesta na sociedade de consumo. Cada vez mais vê-se uma sociedade que se esforça por transformar tudo em mercadoria, ao mesmo tempo em que exclui o diferente, aquele que não exibe objetos padronizados de consumo (BAUMAN, 2008). Isso afeta de forma significativa especialmente crianças e jovens, na medida em que são sujeitos em processo de constituição física, psíquica e emocional, sofrendo profundamente as consequências da falaciosa promessa de abundância para todos recorrente na sociedade de consumo, uma vez que essa promessa se confronta com a exclusão das camadas sociais que se deparam com uma escassez rotineira. Diante disso, podese dizer que há uma crise ética e não apenas econômica.

A sociedade de consumo desde seu início vem ampliando os espaços de segregação social, definindo os limites de quem pode ou não usufruir de suas benesses. A mídia publicitária destaca que todos podem ter acesso aos mais diversos bens de consumo, expondo em seus veículos de comunicação produtos extremamente caros e verdadeiramente inacessíveis à grande parcela da população brasileira, especificamente.

Essa sociedade faz uma promessa democrática falaciosa, na qual o que há por trás é um conjunto de instituições que, sob a lógica do mercado, ampliam o abismo entre "os de fora" e “os de dentro". A inclusão é concebida numa perspectiva de poder aquisitivo e não de cidadania. Trata-se de um sistema socioeconômico que não atende às mais urgentes necessidades das massas e que é legitimado por sujeitos consumidores apenas. Isso porque a cidadania tem se distanciado das práticas subjetivas cotidianas na sociedade de consumo e a democracia é o "único freio possível” (FERNANDES, 2008, p. 167) à revolução burguesa e ao que dela resultou.

Sob o monopólio privado da cultura 'a tirania deixa o corpo livre e vai direto à alma. O mestre não diz mais: você pensará como eu ou morrerá. Ele diz: você é livre de não pensar como eu; sua vida, seus bens, tudo você há de conservar, mas de hoje em diante você será um estrangeiro entre nós'. Quem não se conforma é punido [...]. Obstinadamente, insistem (as massas) na ideologia que as escraviza. O amor funesto do povo pelo mal que a ele se faz chega a se antecipar à astúcia das instâncias de controle. (ADORNO, HORKHEIMER, 1985, p. 110, grifos do autor).

\section{POLÊM!CA $\mid$ LABORE}

Polêmica - Revista Eletrônica da Uerj - Rua São Francisco Xavier, 524, $1^{\circ}$ andar bloco D, sl.1001 • Tels.: +55 21 2334-4088 / 4087 • http://www.e-publicacoes.uerj.br/index.php/polemica/index http://www.labore.uerj.br • laboreuerj@yahoo.com.br 
Ainda que Adorno e Horkheimer tenham escrito esse trecho no livro "A dialética do esclarecimento", que data de 1947, exatamente no período após a Segunda Guerra Mundial, em um contexto de regimes totalitários (nazismo, fascismo, stalinismo, maoísmo e outras variações) existentes em diversos países, é um texto que permanece atual. Isso se consideramos a fragilidade do nosso Estado democrático frente aos casos de corrupção expostos recentemente no Brasil e à esporádica participação sociopolítica da população, pois esta, em sua grande maioria, composta por sujeitos consumidores (BAUMAN, 2008) conformados em viver para adquirir um ou outro produto de consumo, que se eximem de responsabilidades políticas, compreendendo a política sempre como algo "fora", exterior a si e não parte de suas práticas cotidianas e produções subjetivas.

A ideia de sociedade de consumo é exposta também extensamente na obra de Baudrillard (2009) como composta por objetos de consumo tomados além do seu valor de uso e de troca, detentores de um valor signo que lhes é atribuído pela tecnologia midiática como forma de ampliar os desejos do sujeito em consumi-lo justamente para além dos dois primeiros valores. Para esse autor, essa não seria uma sociedade da abundância como veicula os mass media, mas sim de escassez e exclusão, pois apenas está incluído na medida em que se enquadra. Nem tudo pode ser para todos. A temática da sociedade de consumo tem sido alvo também de reflexões por Bauman (2008), segundo o qual, pode-se falar de uma "sociedade de consumidores", pois se trata de "[...] um tipo de sociedade que [...] 'interpela' seus membros [...] basicamente na condição de consumidores" (BAUMAN, 2008, p. 70). O sujeito passa a viver de acordo com os imperativos do mercado e não segundo um consenso lógico estabelecido intersubjetivamente que resguarde valores de humanidade.

$\mathrm{Na}$ sociedade de consumo, a ideia de sujeito autônomo está atrelada à de sujeito consumidor. Autonomia nesse artigo, entretanto, não é entendida como tal e nem como independência absoluta, mas como um "estar com" a partir de uma perspectiva não alienada, consciente (ADORNO, 2011), isto é, a partir da noção de que o sujeito autônomo se reconhece criticamente, bem como tem um entendimento crítico de suas relações com os demais. Portanto, capaz de exercer seus deveres e direitos e lutando pela garantia destes para a vida em uma sociedade mais democrática e justa.

Diante desse quadro de desamparo ético promovido por uma "indústria cultural" (ADORNO, HORKHEIMER, 1985) excludente, compreende-se que a educação, especialmente

\section{POLÊM!CA $\mid$ LABORE}

Polêmica - Revista Eletrônica da Uerj - Rua São Francisco Xavier, 524, $1^{\circ}$ andar bloco D, sl.1001 • Tels.: +55 21 2334-4088 / 4087 • http://www.e-publicacoes.uerj.br/index.php/polemica/index http://www.labore.uerj.br • laboreuerj@yahoo.com.br 
através da instituição escolar, enquanto espaço para práticas favorecedora do desenvolvimento subjetivo e, consequentemente, social, deveria viabilizar produções de saberes que culminasse em transformações necessárias para superação da crise da democracia. Crise essa caracterizada pela falência de suas instituições e pela incapacidade de seus indivíduos exercerem a cidadania. Sabe-se, entretanto, que a escola não surgiu com esse objetivo, se não para justamente o contrário disso (FOUCAULT, 1999).

Somado a isso, temos a noção de "saberes sujeitados", apresentada por Foucault (2016) quando falou acerca da arqueologia enquanto método de investigação dos discursos e da hierarquia do poder da ciência, na qual alguns saberes são entendidos como inferiores e, portanto, os discursos que perpassam esses saberes são tomados como desqualificados e insuficientes. Pode-se dizer que o discurso da criança, ou mesmo do jovem, no ambiente escolar é compreendido, na maior parte do tempo, como aquele que produz um saber inferior dentro da hierarquia escolar (LIMA, 2016; PATTO, 2010). A criança, nessa perspectiva, é desautorizada inclusive quando diante de uma prática autônoma e criativa no esforço por aprender, por exemplo, no caso de um aluno que somente subvertendo uma norma conseguiu realizar uma atividade solicitada pela professora em sala de aula e foi duramente recriminado por isso (QUIXADÁ, 2015).

Essa desautorização ou não escutar o que a criança tem a dizer implica tanto uma compreensão limitada sobre o seu estágio de desenvolvimento, mas também pode ter relação com o fato de ela não ser economicamente produtiva. É contraditório, entretanto, que ela seja potencialmente consumidora, pois a indústria cultural, tal como descreveram Adorno e Horkheimer (1985), está atenta ao que a criança deseja e, cada vez mais, investe pesado em mecanismos de sedução no intuito de ampliar o universo a ser consumido por ela. No que se refere à sua competência social e política, contudo, ela é subestimada, até porque isso reflete a lógica dessa sociedade que visa manter as pessoas na condição de consumidoras e não de sujeitos criativos e criticamente esclarecidos. Nesse processo conta-se com as práticas da instituição escolar, as quais têm reproduzido essa lógica, especialmente, na escola pública, em que se encontram, além de tudo, crianças e jovens de classes economicamente desfavorecidas e, majoritariamente, de origem negra ou indígena. Tudo isso são elementos que levam à reprodução de relações de poder historicamente persistentes e legitimadas pelas instituições sociais.

\section{POLÊM!CA $\mid$ LABORE}

Polêmica - Revista Eletrônica da Uerj - Rua São Francisco Xavier, 524, $1^{\circ}$ andar bloco D, sl.1001 • Tels.: +55 21 2334-4088 / 4087 • http://www.e-publicacoes.uerj.br/index.php/polemica/index http://www.labore.uerj.br • laboreuerj@yahoo.com.br 
Ao questionar acerca da relação entre poder e economia, Foucault (2016) concluiu que não se pode analisar economicamente o poder porque ele "não se dá, nem se troca, nem se retoma, mas que ele se exerce e só resiste em ato." (FOUCAULT, 2016, p. 15). Para ele, no poder existe um mecanismo fundamental que é a repressão, a qual também afeta as relações econômicas:

[...] as relações de poder, tais como funcionam numa sociedade como a nossa, têm essencialmente como ponto de ancoragem uma certa relação de força estabelecida em dado momento, historicamente precisável, na guerra e pela guerra. E, se é verdade que o poder político para a guerra, faz reinar ou tenta reinar uma paz na sociedade civil, não é de modo algum para suspender os efeitos da guerra ou para neutralizar o desequilíbrio que se manifestou na batalha final da guerra. O poder político, nessa hipótese, teria como função reinserir perpetuamente essa relação de força, mediante uma espécie de guerra silenciosa, e de reinseri-la nas instituições, nas desigualdades econômicas, na linguagem, até nos corpos de uns e de outros. (FOUCAULT, 2016, p. 15-16).

A articulação que se pode fazer entre essa proposição foucaultiana e a temática desse artigo é que a sociedade de consumo engendra, portanto, uma guerra silenciosa, tendo como arma uma indústria cultural produtora de ideais que sustentem relações de força historicamente instituídas e legitimadas, em que alguns discursos são tomados como inferiores e de desrazão.

Essa negação à competência discursiva, portanto, sustenta-se em uma sociedade que fomenta uma dominação simbólica pautada em uma hierarquia de padrões estéticos e subjetivos (BOURDIEU, 2009) para se estar e vivenciar o mundo e que reprime modos de subjetivação e de saberes que se apresentem como alternativa a essa padronização, haja vista, por exemplo, o conceito de "saberes sujeitados", apresentado por Foucault (2016). Ainda mais quando se sabe que, historicamente, no Brasil as produções subjetivas da criança e do adolescente, especialmente em situação de pobreza, são caracterizadas sob olhares de subalternização, de desconfiança, e de controle, uma vez que representariam um risco, um perigo (COIMBRA, NASCIMENTO, 2008). Assim, no que se refere à criança, como possibilitar a aprendizagem sem o reconhecimento do seu potencial enquanto sujeito ativo e capaz de participar e produzir saberes, bem como novas práticas sociais que incluam essa participação?

Nesse sentido, a formação dos professores está em xeque. É lá que essas relações de poder podem ou não ser pensadas e questionadas. O professor será aquele que, uma vez, dentro da escola vai reproduzir uma cultura política de repressão que nega o saber infantil ou vai superar práticas pedagógicas que colocam o aprendiz sempre na condição do não saber ou de

\section{POLÊM!CA $\mid$ LABORE}

Polêmica - Revista Eletrônica da Uerj - Rua São Francisco Xavier, 524, $1^{\circ}$ andar bloco D, sl.1001 • Tels.: +55 21 2334-4088 / 4087 • http://www.e-publicacoes.uerj.br/index.php/polemica/index http://www.labore.uerj.br • laboreuerj@yahoo.com.br 
um saber inferior? Quais relações seriam possíveis em sala de aula, considerando esta como um microespaço que reflete a realidade social (VYGOTSKY, 1998)?

\section{Reconhecimento das possibilidades do Ser Criança}

Na sociedade de consumo contemporânea em que ideais culturais estão vinculados aos ideais de consumo tem-se um cenário social e cultural falacioso que afeta tanto a educação quanto os processos de subjetivação. Como os ideais culturais - padrões estéticos, segurança, sentimento de pertença, felicidade, dentre outros (SEVERIANO, 2004; 2001) - produzidos pela sociedade de consumo contemporânea são internalizados pelas crianças? Como isso afetaria seus processos de subjetivação? As relações estabelecidas pelas crianças nessa sociedade, através das suas interações simbólicas, geram quais implicações para sua estruturação subjetiva?

Compreender essas relações exige uma perspectiva do desenvolvimento mental como processo mediado pela cultura. Nesse sentido, Vygotsky $(2000 ; 1998)$, forneceu amplas contribuições. Para ele, as funções psicológicas superiores se estruturam a partir da configuração histórica da espécie humana bem como da história particular do indivíduo (filogênese, ontogênese, sociogênese e microgênese). Considerando ainda que as relações estabelecidas entre o indivíduo e seu contexto cultural para apropriação de informações e significados são mediadas pela linguagem (VYGOTSKY, 2000). De acordo com esse autor, portanto, o sujeito pensa e age no mundo construindo significados e recriando a cultura em virtude da mediação cultural. Portanto, entre sujeito e cultura existiria uma interação dinâmica em constante processo de produção e reprodução de significados. A partir de suas observações, Vygotsky $(2000 ; 1998)$ entendia que o desenvolvimento mental do indivíduo está estreitamente vinculado às relações que ele estabelece com o ambiente social. Para ele, as funções psicológicas superiores são próprias do pensamento humano e resultam das interações que o indivíduo estabelece com a cultura. Esse tema é central em sua teoria, pois o processo de representação mental, segundo ele, tem origem social e é mediado simbolicamente pelos signos, pelas palavras que classificam e organizam o real (VYGOTSKY, 2000).

De acordo com o autor, linguagem e pensamento têm raízes genéticas diferentes e desenvolvimentos independentes até certo momento, quando aos dois anos, aproximadamente, a fala se torna intelectualizada e o pensamento verbalizado. A necessidade de comunicação, de

\section{POLÊM!CA $\mid$ LABORE}

Polêmica - Revista Eletrônica da Uerj - Rua São Francisco Xavier, 524, $1^{\circ}$ andar bloco D, sl.1001 • Tels.: +55 21 2334-4088 / 4087 • http://www.e-publicacoes.uerj.br/index.php/polemica/index http://www.labore.uerj.br • laboreuerj@yahoo.com.br 
compartilhar signos que significam ideias, afetos e pensamento com os outros é o que origina a linguagem entre os humanos (OLIVEIRA, 1993). Já o pensamento evolui da inteligência prática fazendo uso de instrumentos para uma inteligência em que se solucionam operações mentais através de operações externas e concretas e, posteriormente, para a memória lógica, o pensamento abstrato e a linguagem interior (VYGOTSKY, 2000).

A linguagem, para Vygotsky (2000), possui outra função, além de intercâmbio social (comunicação): a de pensamento. É a partir dessa função que o sujeito adentra no universo da ordenação, classificação e categorização conceitual dos objetos e situações do mundo real por um processo que esse autor chamou de "formação de conceitos". Esse teórico estava, portanto, interessado em compreender como o indivíduo adquire e organiza o conhecimento, a partir de sua dimensão simbólica, uma vez que ele entendia a consciência como sistema resultado da interação intersubjetiva e culturalmente mediado pela linguagem.

Daí porque, para ele, a criança está impregnada desde que nasce pela linguagem compartilhada no seu contexto social e toda a carga de significados que esse sistema atribui ao real. Vygotsky (2000) propôs uma concepção trinária (e não binária como na linguística tradicional) do signo linguístico, segundo a qual esse seria composto por um significante, um significado, mas também pelo sentido que compõe a história da construção do significado na consciência e que pode ser particular, mas é sempre histórico e dinâmico.

Na perspectiva da composição sócio histórica do desenvolvimento tem-se o conceito de sociologia da infância. Sarmento (2008) ao descrever o propósito da sociologia da infância aponta para a necessidade de considerar a sociedade sob a ótica do fenômeno social infância como também considera importante dar visibilidade às crianças como atores sociais, produtores de sentidos que afetam a dinâmica das relações sociais para se ter uma compreensão mais justa da rede social e do próprio desenvolvimento da criança. Esse autor ressalta a relevância desse novo campo de saber na busca por compreender o lugar ocupado socialmente pelas crianças e o olhar social sobre a categoria geracional infância.

[...] a Sociologia da Infância desenvolve-se contemporaneamente, em boa parte, por necessidade de compreensão do que é um dos mais importantes paradoxos atuais: nunca como hoje as crianças foram objeto de tantos cuidados e atenções e nunca como hoje a infância se apresentou como a geração onde se acumulam exponencialmente os indicadores de exclusão e de sofrimento. (SARMENTO, 2008, p. 19).

\section{POLÊM!CA $\mid$ LABORE}

Polêmica - Revista Eletrônica da Uerj - Rua São Francisco Xavier, 524, $1^{\circ}$ andar bloco D, sl.1001 • Tels.: +55 21 2334-4088 / 4087 • http://www.e-publicacoes.uerj.br/index.php/polemica/index http://www.labore.uerj.br • laboreuerj@yahoo.com.br 
A crítica que esse autor faz desemboca nas análises sobre a sociedade de consumo, a qual é essencialmente paradoxal, pois na medida em que afirma incluir, cria mecanismos de exclusão. A inserção das crianças nessa sociedade dá-se apenas na condição de consumidoras, busca-se escamotear qualquer possibilidade de sua participação política; além disso, estabelece e amplia o abismo entre as diferentes infâncias.

Ao considerar-se, porém, a criança como produtora de cultura, conforme teoriza Sarmento (2004), e a sociedade como um processo dialético e não linear, fica mais fácil pensar numa transformação das relações de poder que minimizam a grandiosidade dos processos infantis e a importância de uma educação de qualidade para todas as crianças.

\footnotetext{
Sem prejuízo da análise dos factores psicológicos e das dimensões cognitivas e desenvolvimentais que presidem à formação do pensamento das crianças, as culturas de infância possuem, antes de mais, dimensões relacionais, constituem-se nas interacções de pares entre crianças e adultos, estruturando-se nessas relações formas e conteúdos representacionais distintos. (SARMENTO, 2004, p. 21).
}

Desse modo, segundo o referido autor, existem culturas de infância, produzidas a partir de elementos linguísticos, lúdicos, normativos e valorativos por crianças nas mais diversas situações socioeconômicas. Essas culturas além de favorecerem os desenvolvimentos cognitivo, social e emocional das crianças que as compõem, também tornam essas crianças agentes no processo de transformação da realidade que as circundam, pois afetam as relações que elas estabelecem com outras crianças e com os adultos.

As teorias de Vygotsky $(2000 ; 1998)$ e Sarmento $(2008 ; 2004)$ ajudam a situar a criança de modo ativo na esfera social e como sujeito capaz e competente para produzir sentidos sobre sua própria história na relação com os demais. Desse modo, a criança deve ser ouvida, isto é, deve ter sua participação oportunizada pela intervenção pedagógica, que assim contribuiria com eficácia para a efetivação da aprendizagem e para a superação da redução do sujeito criança à condição de consumidor no seu processo de subjetivação e de reconhecimento social.

O sentido da participação é o de se sentir envolvido e disposto a contribuir na vida da comunidade. No caso de crianças e jovens, é entendendo cidadania como participação que se torna possível o exercício dessa por parte desses sujeitos, considerando-os meaning-givers na sociedade, acabando assim por intervir nessa. (CASTRO, MONTEIRO, 2008, p. 283).

\section{POLÊM!CA $\mid$ LABORE}

Polêmica - Revista Eletrônica da Uerj - Rua São Francisco Xavier, 524, $1^{\circ}$ andar bloco D, sl.1001 • Tels.: +55 21 2334-4088 / 4087 • http://www.e-publicacoes.uerj.br/index.php/polemica/index http://www.labore.uerj.br • laboreuerj@yahoo.com.br 
A educação infantil deve incluir nas suas práticas a participação da criança como forma de garantir a elas o exercício da cidadania. Além disso, o ambiente escolar pode e deve ser entendido como espaço de ação política, em que seus sujeitos se relacionem enquanto detentores de direitos e deveres, os quais viabilizariam a existência de uma convivência o mais harmônica possível entre as diferenças subjetivas daqueles que produzem esse ambiente. Daí emergiria o novo, novas possibilidades de sociedade, mais democráticas. As resistências vivenciadas nesse espaço deveriam ser pensadas também como possibilidades criativas, de abertura às novas práticas e, portanto, a uma nova política para os processos de ensinoaprendizagem.

\section{A Educação Infantil como via para a participação política}

Existem várias infâncias mesmo dentro de uma sociedade que busca a padronização dos desejos, isso porque cada sujeito é único e possui sua própria história. Ainda assim, todas elas são uma só quando falamos em "direito à infância". Com relação a isso, a legislação brasileira deu um grande salto nesse sentido quando abraçou o Estatuto da Criança e do Adolescente (Lei 8.069/90), o qual, segundo Castro e Monteiro (2008), é resultado de uma nova representação social da criança e do adolescente pautada no reconhecimento destes enquanto sujeitos de direitos. A cidadania de crianças e jovens foi instaurada no Brasil legalmente a partir desse instrumento de lei; entretanto, ela permanece vinculada à garantia de direitos sociais e não à participação política (CASTRO, MONTEIRO, 2008). A pergunta é: até que ponto as instituições de ensino não partem dessa ótica e deixam esses sujeitos à margem de processos decisórios que compõem o cerne das relações sociais e das práticas pedagógicas no ambiente escolar?

Sabe-se ainda que a partir desse estatuto as políticas públicas voltadas para a infância e a adolescência devem ser elaboradas. O que se vê, contudo, é a não apropriação de forma efetiva desse estatuto, especialmente por parte dos órgãos governamentais. Isso contribui para o abismo cada vez maior entre as crianças que participam dos bens sociais e aquelas que continuam vítimas da violência gerada pela exclusão, a qual é mantida, muitas vezes, pelo conformismo e submissão por parte daqueles que deveriam ser os responsáveis pelo cuidar e pelo educar dessas crianças - frequentemente, pais e professores. Kuhlmann (1996) fala de uma "pedagogia da

\section{POLÊM!CA $\mid$ LABORE}

Polêmica - Revista Eletrônica da Uerj - Rua São Francisco Xavier, 524, $1^{\circ}$ andar bloco D, sl.1001 • Tels.: +55 21 2334-4088 / 4087 • http://www.e-publicacoes.uerj.br/index.php/polemica/index http://www.labore.uerj.br • laboreuerj@yahoo.com.br 
submissão" quando se refere à acomodação dos educadores ao descaso das políticas públicas na área da educação, em especial na educação infantil:

$\mathrm{O}$ atendimento educacional da criança pequena passa a ser visto como um favor aos pobres, que se estabelece por meio do repasse das escassas verbas públicas às entidades assistenciais, legitimando-as como intermediárias na prestação do serviço à população. A baixa qualidade se transforma em algo aceito como natural, corriqueiro e mesmo necessário. (KUHLMANN, 1996, p. 104).

Para Castro e Monteiro (2008), apesar de um grande avanço com relação às representações sociais acerca do lugar da infância na sociedade, ainda existem certas restrições à denominação da criança enquanto cidadã em virtude do seu estágio de desenvolvimento. Sua cidadania está atrelada a uma perspectiva sobre o seu desenvolvimento.

No entanto, essa condição de sujeito de direitos não significou uma condição plena de cidadão. Ainda é considerada uma diferenciação etária qualitativa, delegando-se ao adulto a possibilidade de definição de projetos e de tomada de decisões no que diz respeito à vida de crianças e jovens, uma vez que esses são considerados 'pessoas em desenvolvimento'. (CASTRO, MONTEIRO, 2008, p. 280).

Isso não seria um problema se considerássemos a proteção da criança e a legislação visa essa proteção, entretanto, isso não quer dizer que a criança não possa participar, especialmente, daquilo que ela está ou deveria estar profundamente implicada, como nos seus processos de aprendizagem. Muitas vezes, tira-se da criança o direito à palavra sobre si. É o que Foucault (2015) mostrou no texto "A ordem do discurso", em que esse direito é legitimado de acordo com uma hierarquia discursiva imposta em nome de uma ordem normativa e que tudo o que escapa a essa ordem não é tomado como verdade ou mesmo reconhecido como direito. $\mathrm{O}$ discurso da criança, na maior parte das vezes, é posto nesse lugar de "não verdade". Isso a deixa muito vulnerável nos espaços que ocupa, nos quais poderia/deveria participar mais efetivamente. Trata-se aqui da persistência de uma visão que prioriza focar nas carências, ao invés de promover as potências que toda criança carrega dentro de si.

É sabido que a escola e mesmo a universidade enquanto instituições sociais legítimas têm sido desde o início espaços de práticas que inviabilizam o desenvolvimento de sujeitos democráticos. Isso é esclarecido a partir da análise de que a pedagogia tradicional que surge em meados do século XIX teve como objetivo primordial a consolidação da ideologia burguesa (SAVIANI, 2009; FOUCAULT, 1999) e não o desenvolvimento de sujeitos aprendizes capazes

\section{POLÊM!CA $\mid$ LABORE}

Polêmica - Revista Eletrônica da Uerj - Rua São Francisco Xavier, 524, $1^{\circ}$ andar bloco D, sl.1001 • Tels.: +55 21 2334-4088 / 4087 • http://www.e-publicacoes.uerj.br/index.php/polemica/index http://www.labore.uerj.br • laboreuerj@yahoo.com.br 
de refletir criticamente e de elaborar discursos que recriassem a dimensão social. Para Gramsci (2004), a escola deveria contribuir para o desenvolvimento da responsabilidade autônoma e democrática nos indivíduos, deveria ser uma escola criadora, ou seja, que possibilitasse aos alunos "o aprendizado de métodos criativos na ciência e na vida" (GRAMSCI, 2004, p. 39). Adorno (2011) afirmava que a educação desde a sua fase infantil (Kindergarten) deve ser posta a serviço da formação de sujeitos autônomos e conscientes do mundo e das relações que mediam suas práticas. Só assim haveria uma superação da barbárie, na qual a civilização moderna se encontra imersa, uma vez que o "[...] esclarecimento é a saída dos homens de sua autoinculpável menoridade" (ADORNO, 1985, p. 169).

A educação infantil, portanto, deve voltar seu olhar para a construção de currículos e práticas mais inclusivas, para que as intervenções pedagógicas ocorram de forma a mediar conflitos, a favorecer na criança o desenvolvimento do reconhecimento do outro e possibilitar as trocas necessárias a um bom desenvolvimento social, além de cognitivo. Devem-se ter, em favor de uma educação infantil de qualidade, mudanças urgentes nas práticas e saberes que inundam boa parte das instituições escolares. Essas mudanças resultam também da inclusão do discurso da criança, de suas representações sobre si e sobre o mundo no cotidiano da escola e no processo de ensino-aprendizagem. A criança estaria, assim, exercitando sua competência de sujeito ativo no contexto social que a envolve.

Trata-se de uma realidade da qual não se pode mais fugir: a escola precisa se reinventar e rápido! Os adultos nela inseridos não podem mais tentar dar conta do contexto escolar sozinhos, negando o que dizem as crianças, afastando-as de algo que lhes é de direito: agir no mundo em interação dinâmica com os demais de modo singular e criativo. Devemos proporcionar a elas que ajam como sujeitos competentes para conquistar a aprendizagem, inclusive aquela do âmbito moral, isto é, contribuir para seu desenvolvimento social e moral. Na medida em que isso ocorrer na escola, poderemos vislumbrar concretamente uma educação democrática e para a cidadania.

Quiçá consigamos deixar de nos preocupar tanto em transformar as crianças em algo diferente do que elas são, para pensar se acaso não seria interessante uma escola que possibilitasse a crianças e adultos, professoras, professores, gestores, orientadores, diretores, enfim, a quem seja, encontrar esses devires minoritários que não aspiram a imitar nada, a modelar nada, mas a interromper o que está dado e propiciar novos inícios. (KOHAN, 2007, p. 97).

\section{POLÊM!CA $\mid$ LABORE}

Polêmica - Revista Eletrônica da Uerj - Rua São Francisco Xavier, 524, $1^{\circ}$ andar bloco D, sl.1001 • Tels.: +55 21 2334-4088/4087 • http://www.e-publicacoes.uerj.br/index.php/polemica/index http://www.labore.uerj.br • laboreuerj@yahoo.com.br 
Pesquisas recentes pautadas na escuta das crianças em ambiente escolar (COSTA, 2015; QUIXADÁ, 2015; ROCHA, 2015) mostram o quanto elas têm a dizer e como elas resistem às diversas situações escolares cotidianas que se colocam como muros na sua busca por aprendizagem e subjetivação. Haja vista, por exemplo, os diálogos entre professora e alunos em uma dessas pesquisas: ao investigar as interações discursivas de sete crianças do $1^{\mathrm{o}}$ ano do Ensino Fundamental de duas turmas em uma escola pública de Fortaleza-CE e a construção de suas concepções sobre a linguagem escrita, Quixadá (2015) observou algumas situações de sala de aula, nas quais a professora (representada nos diálogos abaixo pela letra P) de uma das turmas observadas tentava mais frequentemente se valer de uma autoridade instituída para exceder no controle. Por conta disso, as crianças no seu processo de aprendizagem precisavam agir, em várias situações, de modo insubordinado o que acarretava certo prejuízo na relação entre esses atores do cenário escolar, bem como nesse processo em si:
Dia 03/09/13
Margarida (professora) pediu que as crianças escrevessem o nome da brincadeira que é relatada na história Vamos passear no bosque. Depois Bruno (criança) disse:
B: Vamos passear no bosque!
P: 'Vamos passear no bosque'?! Então, vamos escrever!
B: Já está no título! (então, ele levantou da cadeira e foi até o cartaz na parede onde estava escrito toda a história para poder ler o título e depois escrevê-lo).
P: Sentado, Bruno! Escreva do seu jeito! Por que você não pensa no lugar de copiar? Você vai pensar: 'Vamos...' Como é que eu escrevo? São quatro palavras. (porém, tanto Bruno quanto Leo (outra criança) continuavam olhando, 'lendo', várias vezes para o cartaz para poderem escrever.). (QUIXADÁ, 2015, p. 150).

Aconteceu situação semelhante com outro aluno:

Dia 17/09/13

Algumas crianças que estavam sentadas formando um pequeno grupo com quatro mesas estavam lendo em voz alta um cartaz que estava na parede com o texto Vamos passear no bosque e isso pareceu incomodar Margarida que falou: "Leo, sua mesinha não vai participar porque vocês não estavam escutando os amigos." E Leo retrucou com expressão de quem estava contrariado: "Eu tava escutando!". A professora, então, perguntou: "Pois vamos ouvir?" - e ele e Bruno responderam: "Vamos!". Depois disso, entretanto, Leo não participou da atividade em sala, isto é, não respondia aos questionamentos que Margarida fazia à turma sobre o texto. Até que, minutos depois, estão sentadas conversando sobre as brincadeiras que fariam no recreio e a professora pediu que eles guardassem o livro de leitura e pegassem o livro de atividades e disse:

P: Vamos terminar essa tarefa rapidinho porque é bem facinho e a gente já fez a maior parte dela. Na questão 1 leia o texto 'vamos passear no bosque', depois faça a correspondência com a fichinha...

L: Vou fazer não! Vou fazer não! (disse Leo baixinho balançando negativamente a cabeça). (QUIXADÁ, 2015, p. 155-156).

\section{POLÊM!CA $\mid$ LABORE}

Polêmica - Revista Eletrônica da Uerj - Rua São Francisco Xavier, 524, $1^{\circ}$ andar bloco D, sl.1001 • Tels.: +55 21 2334-4088/4087 • http://www.e-publicacoes.uerj.br/index.php/polemica/index http://www.labore.uerj.br • laboreuerj@yahoo.com.br 
Na situação acima, vê-se que o interesse e a participação do aluno na atividade proposta pela professora são afetados pela qualidade da relação entre ambos. Muitas vezes, a professora enfatizava aos gritos que as crianças deveriam fazer suas atividades sozinhas, sem a ajuda do colega (QUIXADÁ, 2015). Talvez ela pensasse que em duplas ou grupos as crianças poderiam gerar alguma desordem, o que causaria um desgaste para ela porque, não necessariamente, isso implicaria em um problema para o aprendizado das crianças. Essas tinham necessidade, vez por outra, de tirar alguma dúvida, fosse com a professora ou com algum colega, especialmente, quando ela não lhes "dava ouvidos":

[...] no dia 03/09/13: a professora Margarida solicitou às crianças que fizessem uma atividade de leitura/escrita sobre a história Vamos passear no bosque e pediu que as crianças procurassem uma palavra grande e uma palavra pequena. Leo tentou mostrar algo que fez à professora, mas ela não lhe deu atenção. Ele parecia não ter entendido o que deveria fazer e Bruno o ajudou, dizendo-lhe: "Tu faz assim ó: num tem esses aqui, né?! Num tem os espaços, né?! Tu não pode escrever muito, tem os espaços. Tu escreve essa daqui ó (sic).”. Então, Leo apagou e refez tudo. Nesse mesmo dia, Leo apresentou dificuldades para escrever a palavra "pão" e Bruno novamente o ajudou, dizendo repetidas vezes: "Pão, pão...". Isso seria para Leo reconhecer o som e associálo à sua grafia? Como Leo ainda não conseguia escrever, Bruno, então, lhe soletrou: "P-A-O e til no A". (QUIXADÁ, 2015, p. 143).

\section{Dia 22/10/13}

Leo perguntou a Bruno: "Ver-me-lhos... Como é que faz o 'lho'?" e Bruno respondeu-lhe: "L, H, O". Leo, então escreveu no seu livro de atividades soletrando em voz alta: "VER-ME-LHOS."

Depois a professora pediu que as crianças escrevessem a palavra floresta do jeito que elas achavam que devia ser e Karina perguntou a Bruno: "Tá certo o meu?" e Bruno respondeu-lhe: "Falta alguma coisa...". (QUIXADÁ, 2015, p. 146).

Nos momentos em que a professora não deu a atenção devida, isso parece ter gerado em Leo um sentimento de falta de sentido. Quando ele buscou ajuda dela parecia interessado, mas depois o que se viu foi um menino enfadado e sem ânimo de continuar com as atividades em sala de aula. Por outro lado, em outra situação, pediu ajuda ao colega. Essa seria uma forma de escapar às limitações à aprendizagem imposta por uma professora que não o ouvia? Uma forma subversiva, mas que levou essa criança a algum aprendizado.

Os atos de insubordinação aconteciam justamente porque a professora não aceitava as conversas entre as crianças na maior parte do tempo. Isso seria porque ela percebia essa prática como uma perturbação da ordem ou como um prejuízo ao andamento do processo de ensinoaprendizagem? O que se viu, entretanto, é que essa "conversa", apesar da não aprovação da professora, foi uma estratégia de aprendizagem e Vygotsky (2000), ao expor sobre a Zona de

\section{POLÊM!CA $\mid$ LABORE}

Polêmica - Revista Eletrônica da Uerj - Rua São Francisco Xavier, 524, $1^{\circ}$ andar bloco D, sl.1001 • Tels.: +55 21 2334-4088/4087 • http://www.e-publicacoes.uerj.br/index.php/polemica/index http://www.labore.uerj.br • laboreuerj@yahoo.com.br 
Desenvolvimento proximal (ZDP), já previa o quanto a mediação feita por outro sujeito, mais experiente, pode favorecer a ampliação da zona de desenvolvimento real de determinado aprendiz. Por exemplo, não apenas o auxílio da professora, mas também aquele realizado por uma criança, com mais experiência e avanços cognitivos do que outra, pode favorecer a aprendizagem dessa criança, ampliando, através da mediação simbólica, sua capacidade de realizar sozinha certas ações intelectuais.

A escola e os professores precisam reinventar seus olhares sobre a criança que aprende; precisam tomá-la como sujeito que tem algo a dizer sobre si e sobre o que as circundas e não as excluir de agir em um processo que também lhes pertence. Do contrário, posteriormente, enquanto adultos, terão dificuldades em apropriar-se criticamente da vida social e política em que estejam inseridos, contribuindo para o agravamento da crise ética. Eis a responsabilidade que urge nas instituições sociais que cercam a criança, em especial, a escola.

Essas interações entre professora e aluno nos apontam um modelo de relação hierárquica em sala de aula que mantém a criança em um lugar de inferioridade e "não saber". A educação escolar costuma ver a criança como objeto e não sujeito da educação. A criança resiste, mas sua resistência é percebida como subversão no sentido pejorativo e não como exercício de um direito: o direito de aprender de forma criativa e singular. Direito esse que contribuiria para o desenvolvimento de um sujeito capaz de se apropriar daquilo que lhe concerne. Na ausência disso, a criança é mantida em um lugar de "obediência", silêncio e, portanto, de passividade, entretanto, criatividade, aprendizagem e desenvolvimento decorrem de ações do sujeito aprendiz.

Exemplos como esses, de relações de poder em sala de aula, aparecem também em escolas particulares, em virtude da historicidade dessa característica, própria do processo de escolarização (FOUCAULT, 1999). Aqui, entretanto, se mostraram situações em uma escola pública, ou seja, como exemplo de uma realidade em que as práticas democráticas não são objetos de interesse e efetivação, pois, infelizmente, ainda se preserva na grande maioria das instituições públicas desse país, e de tanto outros, uma política de exclusão social, econômica e racial (SAVIANI, 2009; MÉSZÁROS, 2008; KUHLMANN, 1996), sentidas pelas próprias crianças, como na situação a seguir:

No dia 16/12/13, um acontecimento me chamou a atenção. Este, talvez, tenha ligação com algumas atitudes de Leo de não conseguir se integrar às atividades.

\section{POLÊM!CA $\mid$ LABORE}

Polêmica - Revista Eletrônica da Uerj - Rua São Francisco Xavier, 524, $1^{\circ}$ andar bloco D, sl.1001 • Tels.: +55 21 2334-4088 / 4087 • http://www.e-publicacoes.uerj.br/index.php/polemica/index http://www.labore.uerj.br • laboreuerj@yahoo.com.br 
Provavelmente, por conta de um sentimento de não pertença e, por isso mesmo, de não competência para estar ali, junto aos demais colegas. Novamente as crianças estão com uma professora substituta, que tematizava com as crianças sobre o tempo. Leo estava agitado, falando coisas engraçadas para os colegas e, num átimo, a professora disse:

P: Se o Leo...

L: Oi?!

P: ...Se o Leo prestasse atenção, ele teria entendido que o tempo agora é aqui... agora... é o tempo presente.

L: Por que sempre eu?! (perguntou ele, parecendo indignado, olhando para Bruno). Porque eu sou neguinho... eu sou neguinho. (QUIXADÁ, 2015, p. 160).

O racismo está explícito ou implícito nos mais diversos espaços e instituições e mesmo que o acesso à escola pública seja mais democrático do que à escola particular, nunca é demais questionar os motivos da fragilidade na qualidade das instituições públicas para o exercício da cidadania e para o desenvolvimento de subjetividades autônomas, bem como apontar casos em que essa fragilidade persiste. Uma ideologia discriminatória (ARENDT, 2012) tem a função de manter relações de poder que buscam manter determinados grupos de pessoas afastados dos direitos sociais e da ação política.

\begin{abstract}
A riqueza, o prestígio social e o poder ficam concentrados em alguns círculos sociais, que usam suas posições estratégicas nas estruturas políticas para solapar ou neutralizar as demais forças sociais, principalmente no que se refere ao uso do conflito e do planejamento como recursos de mudança sociocultural. (FERNANDES, 2008, p. 149).
\end{abstract}

A educação não pode mais compactuar com isso, com práticas culturais homogeneizadoras e, ao mesmo tempo, como instrumento de uma rede simbólica e real de exclusão material e subjetiva. É preciso uma reconstrução ética e política no âmbito, por exemplo, da educação infantil, em que a criança seja reconhecida também enquanto produtora de narrativas sobre si e sobre o outro, as quais constituem seus processos de aprendizado e subjetivação e que isso não precise emergir apenas como subversão.

Para Hannah Arendt (2016), a educação possui uma ambiguidade em que o desaparecimento da autoridade não é possível, mas não se trata de ausência de autoridade. É justamente por ter um poder instituído que a professora poderia optar por ouvir o que dizem as crianças e, assim, preservar o que há de novo e revolucionário nelas (ARENDT, 2016), contribuindo para o desenvolvimento de suas competências participativas, possibilitando situações em que haja uma alternância mais constante entre locutor e interlocutor nas interações

\title{
POLÊM!CA $\mid$ LABORE
}

Polêmica - Revista Eletrônica da Uerj - Rua São Francisco Xavier, 524, $1^{\circ}$ andar bloco D, sl.1001 • Tels.: +55 21 2334-4088 / 4087 • http://www.e-publicacoes.uerj.br/index.php/polemica/index http://www.labore.uerj.br • laboreuerj@yahoo.com.br 
discursivas em sala de aula. É preciso uma nova política nesse espaço que promova uma maior participação da criança e que não se instaure um muro entre o professor e aquele que aprende.

\begin{abstract}
A educação é o ponto em que decidimos se amamos o mundo o bastante para assumir a responsabilidade por ele e, com tal gesto, salvá-lo da ruína que seria inevitável não fosse a renovação e a vida dos novos e dos jovens. A educação é, também, onde decidimos se amamos nossas crianças o bastante para não expulsá-las de nosso mundo e abandoná-las a seus próprios recursos, e tampouco arrancar de suas mãos a oportunidade de empreender alguma coisa nova e imprevista para nós, preparando-as em vez disso com antecedência para a tarefa de renovar o mundo comum. (ARENDT, 2016, p. 307).
\end{abstract}

\title{
Considerações finais
}

Em tempos de ataque à democracia e de ampliação da polarização política, social e econômica, uma educação que se paute em uma nova ética e que não perca seu papel de promover processos de aprendizagem é o desafio que se lança para o presente, para o aqui e agora. E ainda que as problemáticas lançadas nesse artigo sobre os mecanismos de exclusão presentes na sociedade de consumo sejam uma constante na vida social brasileira, pode-se perceber que, cotidianamente, existem possibilidades de superação das mesmas: por meio de ações de homens e mulheres; das fantasias e ações das crianças; e ainda das práticas potencialmente transformadoras vivenciadas no ambiente escolar, apesar de todas as limitações para isso, que ainda persistem.

Respeitadas as diferenças entre ambos, tanto quanto o adulto, a criança deve participar do tecido social, de modo que o respeito à sua dignidade e ao seu potencial sejam preservados para que ela construa gradativamente a capacidade de exercitar sua cidadania. Assim, em parceria com os outros, que ela possa ser mais uma na busca por solidificar um processo democrático que na sociedade brasileira atual, especificamente, se encontra fluido e escorregadio.

É, portanto, através do reconhecimento das várias culturas de infância e da possibilidade de transformação da realidade da educação infantil, a partir, inclusive, do que a criança tem a dizer que podemos pensar a superação das desigualdades sociais e das políticas públicas excludentes que elevam a profundidade da segregação da infância brasileira. Retomando a reflexão sobre a atitude daquela criança que assistia à brincadeira das outras, há de se pensar que ela guardava fantasias enquanto estava ali paralisada olhando aquelas que brincavam e que

\section{POLÊM!CA $\mid$ LABORE}

Polêmica - Revista Eletrônica da Uerj - Rua São Francisco Xavier, 524, $1^{\circ}$ andar bloco D, sl.1001 • Tels.: +55 21 2334-4088 / 4087 • http://www.e-publicacoes.uerj.br/index.php/polemica/index http://www.labore.uerj.br • laboreuerj@yahoo.com.br 
ela era também produtora de sentidos sobre sua vida longe dali, com seus pares, apesar disso, porém, havia um desejo de participação naquilo que, por exclusão, ela não tinha acesso.

Algumas questões, no entanto, permanecem: como esse lugar “de fora", de exclusão dos bens de consumo pode ser vivido, por exemplo, no ambiente escolar? A escola da menina do início do texto seria mais um lugar que reproduz situações de exclusão e alienação, isto é, de negação do direito de aprender de modo ativo e criativo? E, ainda, as reflexões aqui apresentadas nos levam à seguinte questão para escritos futuros: como formar os adultos que atuam nos espaços escolares para novos olhares sobre o ser criança?

\section{Referências}

ADORNO, T. Educação e emancipação. São Paulo: Paz e Terra, 2011.

ADORNO, T.; HORKHEIMER, M. Dialética do esclarecimento. Rio de Janeiro: Jorge Zahar Editor, 1985.

ARENDT, H. Origens do totalitarismo. São Paulo: Companhia das Letras, 2012.

Entre o passado e o futuro. São Paulo: Perspectiva, 2016.

COSTA, É. A. G. de A. Com que diferenças se fazem adultos e crianças na escola: uma analítica das posições discursivas pela ótica da fronteira e da experimentação. Tese (Doutorado em Educação) - Faculdade de Educação, Universidade Federal do Ceará, Fortaleza, 2015.

BAUDRILLARD, J. La societé de consommation. Paris: Éditions Denoël, 2009.

BAUMAN, Z. Vida para consumo. Rio de Janeiro: Jorge Zahar Ed., 2008.

BOURDIEU, P. O poder simbólico. Rio de Janeiro: Bertrand Brasil, 2009.

CASTRO, L. R.; MONTEIRO, R. A. de P. A concepção de cidadania como conjunto de direitos e sua implicação para a cidadania de crianças e jovens. Psicologia Política, v. 8, n. 16, p. 271-284, jul./dez. 2008.

COIMBRA, C.; NASCIMENTO, M. L. do. A produção de jovens perigosos: a quem interessa? Rio de Janeiro: [s.n.], 2008.

DELACOURS-LINS, S. Representações da leitura no início da alfabetização. In: CRUZ, S. H. V.; PETRALANDA, M. (Org.). Linguagem e educação da criança. Fortaleza: Editora UFC, 2003.

O que não dá pra falar dá, pra desenhar: linguagem implícita nos desenhos dos aprendizes leitores. In: DELACOURS-LINS, S.; CRUZ, S. H. V. (Org.). Linguagens, literatura e escola. Fortaleza: Editora UFC, 2006.

FERNANDES, F. Sociedades de classes e subdesenvolvimento. São Paulo: Global, 2008.

FOUCAULT, M. História da Sexualidade I: a vontade de saber. Rio de Janeiro: Edições Graal, 1999.

A ordem do discurso. São Paulo: Edições Loyola, 2015.

\section{POLÊM!CA $\mid$ LABORE}

Polêmica - Revista Eletrônica da Uerj - Rua São Francisco Xavier, 524, $1^{\circ}$ andar bloco D, sl.1001 • Tels.: +55 21 2334-4088 / 4087 • http://www.e-publicacoes.uerj.br/index.php/polemica/index http://www.labore.uerj.br • laboreuerj@yahoo.com.br 
FOUCAULT, M. Em defesa da sociedade: curso no Collège de France (1975-1976). São Paulo: Editora WMF Martins Fontes, 2016.

GRAMSCI, A. Os intelectuais. O princípio educativo. Jornalismo. In: Cadernos do Cárcere. Rio de Janeiro: Civilização Brasileira: 2004. V. 2.

KOHAN, W. O. Infância, estrangeiridade e ignorância - ensaios de filosofia e educação. Belo Horizonte: Autêntica, 2007.

KUHLMANN, Jr. M. Infância e educação: uma abordagem histórica. Porto Alegre: Mediação, 1996.

LIMA, V. C. O. de. Alunos abjetos: etnografia da inclusão numa escola Municipal de Fortaleza. 2016.Tese (Doutorado em Educação) - Faculdade de Educação, Universidade Federal do Ceará, Fortaleza, 2016.

MÉSZÁROS, I. A educação para além do capital. São Paulo: Boitempo, 2008.

OLIVEIRA, M. K. Vygotsky: aprendizado e desenvolvimento um processo sócio-histórico. São Paulo: Scipione, 1993.

PATTO, M. H. S. A produção do fracasso escolar: histórias de submissão e rebeldia. São Paulo: Casa do Psicólogo, 2010.

QUIXADÁ, L. M. Ciranda de palavras, auroras de sentido: interação discursiva em sala de aula e construção da concepção da criança sobre a linguagem escrita. Tese (Doutorado em Educação) - Faculdade de Educação, Universidade Federal do Ceará, Fortaleza, 2015.

ROCHA, N. M. F. D. Relações étnico-raciais e educação infantil: dizeres de crianças sobre cultura e história africana e afro-brasileira na escola. Tese (Doutorado em Educação) - Faculdade de Educação, Universidade Federal do Ceará, Fortaleza, 2015.

SARMENTO, M. J. As culturas da infância nas encruzilhadas da segunda modernidade. In: SARMENTO, M. J.; CERISARA, A. B. (Org.) Crianças e miúdos: perspectivas sociopedagógicas da infância e educação. Edições Asa, 2004.

Sociologia da infância: correntes e confluências. In: SARMENTO, M. J.; GOUVEA, M. C. S. (Org.). Estudos da infância: educação e práticas sociais. Petrópolis: Vozes, 2008.

SAVIANI, D. Escola e democracia. Campinas: Autores Associados, 2009.

SEVERIANO, M. F. V. Narcisismo e publicidade: uma análise psicossocial dos ideais de consumo na contemporaneidade. São Paulo: Annablume, 2001.

Cultura de consumo segmentada: a marca da diversidade/desigualdade social. In: COSTA, M. F. V. et. al. Diversidade cultural e desigualdade: dinâmicas identitárias em jogo. Fortaleza: Editora UFC, 2004.

VYGOTSKY, L. S. A formação social da mente: o desenvolvimento dos processos psicológicos superiores. São Paulo: Martins Fontes, 1998.

A construção do pensamento e da linguagem. São Paulo: Martins Fontes, 2000.

Recebido em: 19/02/2019.

Aceito em: 30/03/2019.

\section{POLÊM!CA $\mid$ LABORE}

Polêmica - Revista Eletrônica da Uerj - Rua São Francisco Xavier, 524, $1^{\circ}$ andar bloco D, sl.1001 • Tels.: +55 21 2334-4088 / 4087 • http://www.e-publicacoes.uerj.br/index.php/polemica/index http://www.labore.uerj.br • laboreuerj@yahoo.com.br 